\title{
A linguagem como construção $X$ desconstrução das identidades diversas: multi/interculturalidade escolar
}

The language as construction $\mathrm{X}$ deconstruction of various identities:

Multi/School Interculturality

\section{Lilia Odete Nantes de Oliveira}

lilinantes@unigran.br

Mestre em Educação, UCDB - MS

\section{Resumo}

O objetivo deste estudo é entender como a multi/interculturalidade influencia no processo de construção da identidade dos estudantes das cidades fronteiriças. Uma das maiores especificidades que marca esse contato são as línguas faladas no local: a língua portuguesa, a castelhana, a guarani e a mistura das três, formando assim um dialeto “joporá”, que se caracteriza como pressuposto para a (re)criação cultural e identitária. Palavras-chave: Identidade; fronteira; multi/interculturalidade.

\begin{abstract}
This study aims at understanding how multi/interculturality influences the process of identity building for students of frontier cities. One of the greatest specificities of this contact is the languages spoken: Portuguese, Castilian, Guarani and the mixture of the three, forming a "joporá" dialect, which is characterized as an assumption for the (re)creation of both culture and identity.
\end{abstract}

Keywords: Identity; Border; Multi/interculturality. 


\section{Introdução}

Para avançar sobre a multi/interculturalidade no ambiente escolar, este trabalho pretende-se tratar brevemente a questão da construção e desconstrução das identidades múltiplas nos espaços de fronteira. Para isso, baseamo-nos nas ideias de Candau e Leite (2007) e entendemos que tal desconstrução refere-se também às questões de discriminação e preconceito, quando buscamos desnaturalizá-los, além de, simultaneamente, questionar pressuposições monoculturais e etnocêntricas que podem coexistir em ambientes formais de educação (escola) ou se manifestar de alguma forma no cotidiano.

Consideramos, portanto, que as identidades culturais atuais não são inflexíveis, tampouco imutáveis: são efeitos fugazes, constantes e transitórios dos processos de identificação. Com a leitura de Santos, percebemos que as identidades consideradas "sólidas", em geral, não costumam ensejar "negociações de sentido, jogos de polissemia, choques de temporalidades em constante processo de mudança, responsável em última instância pela sucessão de configurações hermenêuticas que de tempos para tempos dão corpo e vida a tais identidades" (1994, p.31).

Considerando isso, assumimos a escolha de uma perspectiva intercultural da multiculturalidade (utilizada como categoria descritiva, analítica, sociológica ou histórica em FLEURY, 2003, e FLEURY; AZIBEIRO, 2008) em sinergia com o multiculturalismo crítico proposto por McLaren e discutido por Candau e Fleury. Corroboramos a ideia de que a interculturalidade supõe a relação entre diferentes grupos sociais e culturais, com referência na concepção do “(...) reconhecimento do direito à diversidade e na luta contra todas as formas de discriminação e desigualdade social e tenta promover relações dialógicas e igualitárias entre pessoas e grupos que pertencem a universos culturais diferentes" (CANDAU, 2008, p.47).

Podemos pensar as identidades como 'identificações' em andamento. Já as identificações são plurais, tomadas pela ordenação hierárquica das distinções e pelas diferenças. Assim, em uma perspectiva multi/intercultural, as identidades passam a ser compreendidas e desenvolvidas com base em relações intensas e tensas entre os distintos indivíduos (FLEURY, 2006).

Cabe reiterar, com base nas ideias de Forquin (2000, apud CANDAU, 2008; LEITE, 2007), a importância e a riqueza da coexistência do encontro e da interação entre indivíduos de identidades culturais distintas, uma vez que isso permite que cada um alargue e enriqueça 
suas perspectivas a partir das perspectivas dos outros, mesmo diante de eventuais riscos de desestabilização e conflito.

Sabe-se que a resposta, com êxito, à questão da identidade se traduz sempre em uma reinterpretação fundadora que converte o déficit de sentido da pergunta no excesso de sentido da resposta. E o faz, instaurando um começo radical que combina o próprio e o alheio, o individual e o coletivo, a tradição e a modernidade (SANTOS, 1994). Assim, pode influenciar na construção e na desconstrução das identidades múltiplas dos habitantes fronteiriços através de relações econômicas ou socioculturais, pois quando o indivíduo está em constante convivência com diferentes culturas, sua identidade e o modo como é reconhecido podem mudar frequentemente por adquirir uma "nova" identidade que pode ser territorial e definida como um tipo de identidade que se expressa na relação de pertencimento a um grupo a partir da delimitação de uma escala territorial de referência identitária (SAID, 2003, e SOUCHAUD, 2007).

$\mathrm{Na}$ busca da construção/reconstrução de identidades múltiplas, a instituição escolar precisa ser um espaço de fomento para a educação intercultural, que representa um processo de construção na relação entre pessoas distintas, criando e mantendo um ambiente interativo, criativo, formativo e propício para que cada uma dessas pessoas desenvolva suas respectivas identidades. Dessa forma, acreditamos que para tratar sobre educação intercultural é preciso considerar a perspectiva de que "pode tornar-se possível a dissolução de preconceitos e estereótipos e a produção de processos de subjetivação e constituição de identidades dessubalternizadas" (FLEURY; AZIBEIRO, 2008, p.16).

\section{Identidade e multi/interculturalidade}

A questão da identidade permeada pela multi/interculturalidade suscitou-nos o seguinte questionamento: quando e como esse conceito passou a ser pensado a partir de sua contribuição para o ambiente escolar?

A partir de 1978, as situações relacionadas à diversidade cultural e à interculturalidade repercutiram de forma mais consistente, especialmente após a aprovação pela UNESCO da "Declaração sobre Raça e os Preconceitos Raciais", que conceituou termos imprescindíveis para nortear uma educação intercultural, tais como: o fato de pertencermos a uma mesma espécie e origem, sermos iguais em dignidade e direitos, termos o direito à diversidade e à 
identidade cultural etc., especialmente no que se refere à garantia de mais visibilidade para as temáticas relacionadas a diferenças, identidade e alteridade.

Nestor Canclini (2009) nos ensina que a interculturalidade trata-se de uma condição da sociedade contemporânea, de maneira que, conscientemente ou não, leva à concretização de práticas interculturais em distintas escalas e níveis de ação dos sujeitos.

Canclini (2009) ainda reconhece que a interculturalidade foi se tornando um conceito chave para compreensão da sociedade, especialmente a fronteiriça, uma vez que, em distintas esferas da vivência, somos expostos às situações interculturais de troca e aos contatos com distintas culturas, os quais, por sua vez, possuem um viés espacial já que são vividos por indivíduos em situações cotidianas ao criarem e recriarem um ambiente mais humano.

(...) o que tratamos de ver atualmente (...) é como se reelabora interculturalmente o sentido [de cultura]. Não só dentro de uma etnia nem seguem dentro de uma nação, mas em circuitos globais, superando fronteiras, tornando porosas as barreiras nacionais ou étnicas e fazendo com que cada grupo possa abastecer-se de repertórios culturais diferentes (...) (CANCLINI, 2011, p.43).

Agora, com base nas ideias do professor Lozandro Tedeschi (2008), entendemos que a interculturalidade representa não apenas a coexistência e o reconhecimento da diversidade e da diferença cultural, pois procura promover relações e práticas dialógicas entre grupos culturais distintos, tendo em vista a construção de novas formas de viver e pensar o mundo.

Quanto ao nível social, a interculturalidade orienta os processos baseados no fomento ao intercâmbio entre culturas distintas, nas lutas travadas contra a desigualdade e a discriminação socioeconômica e no aceite e respeito ao direito à diversidade. Desse modo, a interculturalidade refere-se a um processo sem fim, o qual é constantemente construído, intentando fomentar e possibilitar um relacionamento dialógico e democrático entre os grupos sociais e as culturas, superando a simples existência pacífica em um mesmo ambiente. Defendemos, portanto, que tal condição se trata de uma característica fundamental para qualquer processo ser reconhecido como “intercultural” (TEDESCHI, 2008).

Tedeschi (2008) argumenta que a interculturalidade caracteriza-se como uma postura teórica e política que tem por base o diálogo cultural para além do mero reconhecimento do outro. Nessa mesma perspectiva, temos os apontamentos de Fleury (2003), para o qual a interculturalidade representa um termo complexo que engloba diversos contextos socioculturais. 
O que chamamos aqui de intercultura trata-se de uma área complexa, interdisciplinar e transversal, na qual se entretecem múltiplos indivíduos/sujeitos sociais, distintas visões político-epistemológicas, múltiplos contextos e variadas práticas sociais. Ademais, ela enfatiza o caráter relacional e contextual (inter) dos processos sociais e permite reconhecer a complexidade, a polissemia, a fluidez e a relacionalidade dos fenômenos humanos e culturais (FLEURY, 2003).

\section{Interculturalidade transfronteiriça}

Nesse contexto, o conceito de interculturalidade nos auxilia na compreensão das relações estabelecidas entre brasileiros e paraguaios que, mesmo vivenciando conflitos e tensões cotidianas relacionam-se entre si e compartilham elementos culturais e identitários, formam a cultura e a identidade transfronteiriça à medida que essa representa o trânsito e a mobilidade nos quais os sujeitos expressam e vivenciam uma territorialidade híbrida, dinâmica, complexa e múltipla, tal como a própria fronteira.

Entre Brasil e Paraguai, a diversidade e a diferença cultural adquirem uma conotação política e nacional e as relações interculturais representam uma alternativa para o processo histórico de "rivalidade" entre brasileiros e paraguaios, possibilitando a recriação identitária a partir da reelaboração e ressignificação dos elementos culturais e identitários de brasileiros e paraguaios, que, juntos, formam a identidade transfronteiriça.

Entendemos que, pelo fato de possibilitar um "cruzamento de culturas" favorável tanto às hibridizações quanto às relações interculturais, a fronteira trata-se de um "sistema biossocial". No contexto desse artigo, podemos encontrar algumas aproximações com as proposições de Hommi Bhabha (2010), quando esse autor tece algumas considerações a respeito de termos como identidade e diferença cultural.

Em suas abordagens, Bhabha (2010) indica que a terminologia "fronteira" aparece de forma metafórica representando um "entre-lugar", ou seja, um local "entre-culturas" que possibilita a recriação de novos significados e novos sentidos para elementos já existentes. Assim, o acompanhamento dos processos de hibridização entre brasileiros e paraguaios observados na fronteira entre a nação brasileira e a paraguaia, remete à ideia de "entre-lugar" proposta por Hommi Bhabha (2010). 


\section{O processo de hibridização}

Constatamos que um dos principais possibilitadores para as relações de encontros e desencontros culturais entre brasileiros e paraguaios é a escola, especificamente as localizadas no Brasil (TERENCIANI, 2011). Isso porque muitos alunos e alunas paraguaios estudam no Brasil. Mas como isso é possível? A resposta a essa pergunta é simples e complexa ao mesmo tempo: inúmeros pais (paraguaios) registram seus filhos no Brasil. Isso acontece em decorrência de variados motivos, tais como a gratuidade do serviço de registro de nascimento brasileiro e do sistema de educação e saúde públicos inexistentes no Paraguai. Além disso, muitos acreditam que a "nacionalidade brasileira" possibilitará a seus filhos melhores oportunidades de emprego e condições de vida futura, como vagas em universidades, melhores salários etc (TERENCIANI, 2011).

Os filhos do Brasil e os filhos do Paraguai, embora estando em um espaço com proximidade física, vivem conflitos e tensões interétnicos, os quais dão origem a preconceitos, estereótipos sociais e práticas discriminatórias. Contudo, mesmo com tensões e conflitos cotidianos, as culturas e as pessoas continuam se encontrando nos espaços escolares e ultrapassando seus muros pelas novas ideologias construídas, estabelecendo novas estruturas materiais, simbólicas, culturais e socioespaciais.

A escola ganha uma importância central nesse processo de discussão e problematização da alteridade, é um ambiente no qual a interação e o contato entre brasileiros e paraguaios, “(...) pode se tornar uma fonte de relações nas quais o respeito para com as diferenças esteja presente cotidianamente" (TERENCIANI, 2011, p.68).

Nesse sentido, as escolas são espaços carregados de diferentes formas e expressões culturais marcadas pela diversidade de pessoas que se encontram nestes locais em busca de aprendizado. Torna-se, portanto, necessário refletir sobre as práticas educacionais que são desenvolvidas no seu interior, de forma que busquem trabalhar as diferenças existentes, bem como as relações de identificação e diferenciação que ocorrem não apenas no espaço escolar, mas que extrapolam seus muros no desenrolar das práticas sociais cotidianas.

Enfatizamos que, nas escolas fronteiriças, as questões em torno das teorias multiculturais e interculturais podem passar por abordagens intensas e/ou extensas. Entretanto, como afirma Canclini (2009), há uma diferença entre multiculturalismo e multiculturalidade: 
(...) É útil, pelos menos, estabelecer a diferença entre multiculturalidade e multiculturalismo. A multiculturalidade, ou seja, a abundância de opções simbólicas, propicia enriquecimentos e fusões, inovações estilísticas mediante empréstimos tomados de muitas partes. O multiculturalismo, entendido como programa que prescreve cotas de representatividade em museus, universidades e parlamentos, como exaltação indiferenciada das realizações e misérias daqueles que compartilham a mesma etnia ou o mesmo gênero, entrincheirando-se no local sem problematizar sua inserção em unidades sociais complexas de ampla escala (CANCLINI, 2009, p. 26-7).

Nessa perspectiva, observamos que pensar a multiculturalidade é pensar também na abundância de opções simbólicas e nos diálogos interculturais; ao passo que tomar para si uma postura intercultural no ambiente escolar representa muito mais do que simplesmente aceitar a pluralidade e a diversidade cultural, mas se comprometer pela busca de condições mais favoráveis de vida para a sociedade, colocando em questão a organização lógica imposta pelo capitalismo segregacionista homogeneizador mundial (FLEURY, 2003; CANCLINI, 2009, e TERENCIANI, 2011).

Dessa maneira, a vida na fronteira, no "entre-lugares", proporciona um rol de novas possibilidades para os habitantes fronteiriços. Tanto a escola fronteiriça como a própria fronteira podem ser reconhecidas como espaços de distanciamentos, aproximações e trocas, em que os habitantes/estudantes vivem uma múltipla territorialidade.

Ao pensarmos especificamente no processo de ensino-aprendizagem partindo de um posicionamento intercultural, reconheceremos que é "no espaço ambivalente entre os elementos apreendidos e os diferentes contextos a que podem ser referidos, é que pode emergir o novo, ou seja, os processos de criação que podem ser potencializados nos limiares das situações limites" (FLEURY, 2003, p.22).

Ao discutir a função e o papel desempenhado pela escola é inevitável não pensarmos nos elementos culturais presentes de diferentes formas em seu interior e também sua função como representante do Estado, estando a ele ligada, respondendo a determinados interesses e seguindo normas estipuladas. Embora historicamente a escola tenha sido utilizada como instrumento veiculador de uma ideologia nacional (PEREIRA, 1999, e GÁUDIO; BRAGA, 2007), partimos da premissa de que em seu interior há um entrecruzamento de culturas, pois, mesmo no interior de um único país, as culturas são amplas, plurais e dinâmicas e não se restringem a delimitações político-administrativas.

A cultura trata-se, portanto, de uma representação dos símbolos e valores que identificam os significados da existência dos sujeitos, ultrapassando os atributos econômicos e 
políticos, havendo no interior de uma nação uma variedade de culturas em pequenas e grandes escalas que fogem à "homogeneidade nacional".

Dessa forma, a situação de escolas localizadas em áreas de fronteiras internacionais torna-se peculiar, pois além de contarem com a diversidade de gênero, raça, orientação sexual, entre outras, ainda estão em contato com identidades culturais nacionais distintas, que se tornam muito mais visíveis nestes locais.

Uma das maiores especificidades que marcam esse contato nas salas de aula é a língua falada no local; a primeira é representada pelo português e a segunda pelo castelhano e o guarani, ou seja, um número significativo de alunos fala até três idiomas dentro e fora das escolas, havendo também casos de mistura dos três, formando um dialeto próprio, o "joporá", que Pereira (2013) considera como fronteiriço. Esse é um elemento integrador entre brasileiros e paraguaios, que podem se unir por meio da representação da língua falada:

(...) a língua numa área de fronteira não se restringe aos limites territoriais, assumindo uma face que incorpora elementos das diferentes línguas, tornando outra, no caso uma quarta língua, aquela típica do fronteiriço; numa mesma frase, por exemplo, encontra-se uma mescla de português, espanhol e guarani (PEREIRA, 2013, p.57).

Nesse sentido, a postura teórica intercultural em educação na fronteira Brasil-Paraguai representa uma alternativa para trazer para a sala de aula elementos da cultura paraguaia que muitos brasileiros consideram ser inferior e feia por ser diferente do padrão típico europeu ocidental, um dos fundamentos da cultura brasileira.

Além disso, práticas e vivências interculturais, que identificam as respectivas culturas, são vivenciadas por sujeitos de ambas as nacionalidades, tais como: o tereré (bebida típica da fronteira Brasil-Paraguai, produzida à base de erva mate); a chipa e a sopa paraguaia (comidas típicas do Paraguai muito apreciadas pelos brasileiros), entre outras.

Há também a estruturação de laços de parentesco entre brasileiros e paraguaios, principalmente por meio dos casamentos, que unem as culturas e as identidades, gerando novas representações e novos saberes sobre o viver transfronteiriço.

A manifestação da identidade transfronteiriça é, portanto, múltipla, ao passo que congrega distintos atributos e características das culturas provenientes do Brasil e do Paraguai, constituindo uma nova identidade. Nesse sentido, o professor Corrêa alerta, citando uma conversa com Daniel Gade, que a língua é "o mais relevante meio para expressar a 
identidade de um grupo (...) Mais do que isto, a língua interfere em um certo modo de ver, sentir e, talvez mesmo, de se comportar" (2008, p.16).

Nesse ínterim, a escola é um dos principais espaços onde acontecem os discursos identitários, pois nela as comunidades minoritárias passam por situações de desrespeito e estigmatização como é o caso da proibição do uso da própria língua no ambiente escolar (DALINGHAUS, 2009).

\section{Indiscriminação da língua falada}

Faz-se necessário abordar as questões referentes à indiscriminação da língua falada em determinados lugares, principalmente nas regiões de fronteira, bem como à valorização e ao reconhecimento da variedade linguística e, além disso, considerar a forma de falar do "outro", preservando e valorizando, assim, sua identidade e sua cultura.

Ratificamos que nós educadores não podemos permitir a ocorrência do preconceito linguístico, que segundo as ideias de Bagno (2002) pode ser extremamente prejudicial para a educação, uma vez que, por não considerar a diversidade do português falado no Brasil, impõe uma determinada norma linguística como se ela representasse a língua comum a todos, “independentemente de sua idade, de sua origem geográfica, de sua situação socioeconômica, de seu grau de escolarização etc." (BAGNO, 2002, p.15). O autor deixa claro que uma das causas do preconceito linguístico é a maneira como a escola tem atuado, de forma que, ao impor uma norma padrão, a escola não leva em consideração critérios fundamentais para o bom desenvolvimento dos alunos. Dentre esses critérios destaca-se a origem geográfica, no caso deste artigo, a fronteira entre Brasil e Paraguai.

O Brasil, além de apresentar várias línguas indígenas, tem também a língua dos imigrantes, dentre as quais se destacam, na fronteira do Oeste Paranaense com Argentina e Paraguai, o italiano, o alemão e outras, sem mencionar o modo de falar de cada região brasileira, conforme explica Orlandi $(2009$, p.59) “o Brasil tem sua língua oficial, ao lado das muitas línguas indígenas, falares regionais, línguas de imigração etc.”. Por isso, embora a língua oficial do Brasil seja o português, é preciso considerar e respeitar a existência de diversas culturas e identidades sociais, pelo menos dentro do ambiente escolar, já que ele é um dos contextos mais relevantes no qual são consolidados os discursos identitários e a criança está exposta a todas essas situações geradoras de conflitos (MOITA LOPES, 2002). 
Ainda a respeito da língua, acreditamos que se trata de "um dos principais fatores que estabelecem essa identidade étnica" (MEY, 1998, p.71) e, portanto, que a língua identifica e revela a identidade de um indivíduo como pertencente a um determinado grupo étnico. É importante lembrar que a região de fronteira se constitui de vários grupos étnicos, uma vez que essa região é formada por várias culturas, por diferentes povos e, consequentemente, diferentes identidades.

É fundamental que reflitamos cada vez mais sobre as intempéries que a instituição escolar enfrenta ao deparar-se com a discriminação e a estigmatização ao receber alunos "brasiguaios", uma vez que, mesmo com a política e uma tendência da literatura que nos encaminha para um ideal de "escola para todos", esta proposta não pode ser sustentada em situações de conflitos identitários extremamente graves e disruptivos. Essas questões são tratadas, entre outros documentos, nos PCNs, contudo, muitas vezes não são discutidas, não compõem o currículo e nem mesmo são consideradas na prática educacional.

Há alguns anos pesquisadores discutem sobre a necessidade de se repensar o ensinoaprendizagem de alunos de grupos minoritários. Dentre eles, Calvacanti (1999) já chamava nossa atenção a respeito dos contextos brasileiros multiculturais e multilíngues, contextos que já não podem ser vistos como minoritários e devem fazer parte da educação de professores.

Cavalcanti e Moita Lopes (1991), diante da necessidade de formar e sensibilizar professores para o contexto sociolinguístico complexo, propõem, para os cursos de licenciatura, principalmente de Letras, disciplinas que seriam essenciais ao curso. Essas disciplinas nem fazem parte do currículo, por exemplo, Linguística Aplicada, Sociolinguística (Educacional), Iniciação à Pesquisa, Antropologia (Educacional) e Interação em Sala de Aula.

É necessário refletir, rever, repensar e trabalhar as negações, os rechaços e os apagamentos da diversidade, da diferença e dos preconceitos que são decorrentes da prática do monolinguismo e, por consequência, do desrespeito ao multilinguismo cultural brasileiro. Isso em decorrência do maior dos mitos que alimentam a constituição do preconceito linguístico no Brasil: "a língua portuguesa falada no Brasil apresenta uma unidade surpreendente" (BAGNO, 2002, p.15).

Outra questão inquietante é que esse cenário de "monolinguismo linguístico", que considero insustentável em um país como o Brasil, tem se mostrado "eficaz para apagar as minorias, isto é, as nações indígenas, as comunidades imigrantes e, por extensão, as maiorias

\footnotetext{
1 Termo cunhado em meados de 1980 para designar a população de brasileiros que voltaram do Paraguai, mas posteriormente se estenderia aos residentes. Disponível em: http://latinoamericana.wiki.br/verbetes/b/brasilguaios. Acesso em: 20 jan 2018.
} 
tratadas como minorias, ou seja, as comunidades falantes de variedades desprestigiadas do português” (CAVALCANTI, 1999, p.387), como é o caso do aluno brasiguaio. Portanto, deveria ser "regra entrar em uma sala de aula multicultural/multilíngue". Exceção seria encontrar uma sala de aula com "falantes nativos ideais" dentro de uma "comunidade de fala homogênea" (CAVALCANTI, 1999, p.387).

Além disso, percebe-se que a maneira como a escola tem lidado com o aluno brasiguaio não tem solucionado os problemas. Encaminhar o aluno que foi alfabetizado em espanhol e guarani para aulas de reforço não vai resolver suas dificuldades com a aprendizagem de Língua Portuguesa. Uma proposta para tentar amenizar esta situação seria ofertar o ensino de Língua Portuguesa para estrangeiros, uma vez que o modo de ensinar e aprender línguas estrangeiras é diferente de aprender e ensinar a língua materna.

Nesse sentido, o acordo entre Brasil e Paraguai, conforme descrição no instrumento normativo Escolas da Fronteira do MEC (2008) preconiza-se que uma escola que respeite a interculturalidade nos espaços de fronteiras precisa proporcionar distintas formas de exposição à interculturalidade, possibilitando uma exposição sistemática ao:

(...) uso da segunda língua, na medida em que a outra língua passa a fazer parte de maneira cada vez mais presente no cotidiano da escola, onde a criança passa uma parte importante do seu tempo. Esses usos são orais e escritos. A presença de textos na segunda língua, a ser estimulada desde o primeiro contato da criança com a escola, cresce e se diversifica à medida que avançam suas possibilidades de leitura, tornando-se, com o tempo, uma presença constante em todos os atos educativos, das diferentes disciplinas. (...) Uma relação pessoal com um falante nativo da segunda língua. A criança não é exposta somente a usos da segunda língua, mas é possibilitada a formação de um vínculo com uma pessoa que conversará com ela exclusivamente na segunda língua. Esse vínculo emocional é fundamental para a formação de atitudes positivas frente ao idioma e à cultura que ele veicula. É importante além disso observar que o vínculo se dá com um falante nativo da segunda língua, o que possibilita à criança perceber e vivenciar a pragmática que liga língua e cultura. $\mathrm{O}$ reconhecimento da alteridade implica refletir sobre as representações que circulam em uma sociedade a respeito das línguas e das culturas que as contextualizam. Um claro exemplo disso são os estereótipos com os quais se identifica tanto a uma língua como a seus falantes. As línguas, neste sentido, são mais ou menos "fáceis", "alegres", "doces", "musicais", entre outras apreciações estereotipadas. A compreensão destas representações implica reconhecer a complexidade da aprendizagem de outra língua e cultura e, consequentemente, compreender o alcance do esforço pedagógico a ser realizado pela escola. É a partir da informação e da reflexão contínua entre alunos e docentes que estas podem ser ressignificadas. A aula se converte em um espaço para a descoberta das características da segunda língua. (BRASIL, 2008, p.17). 
Proporcionar contato com profissionais do outro país, que têm uma vivência institucional no sistema escolar do seu país, é uma experiência também muito importante para a criança, que vivenciará, no seu contato com professores paraguaios e brasileiros, as tradições pedagógicas institucionais de dois sistemas escolares diferentes.

Destacamos que, por mais que esses aspectos precisem acontecer juntos, a partição durante a contextualização teórica nos possibilita compreender os ganhos que podemos ter se os estudantes não apenas reconhecerem usos da língua, mas também estabelecerem vínculos pessoais junto a essa aprendizagem. Um eventual receio ou medo, decorrentes do desconhecimento do outro, pode virar uma surpresa, uma curiosidade e até mesmo um desejo de aproximação gerado pela vivência de experiências conjuntas significativas.

Entendemos que é preciso, ainda, que as escolas fronteiriças, para além dessa incorporação da segunda língua e de pessoas de outra nacionalidade nas suas rotinas, ampliem a base informacional dos conteúdos escolares, deixando de focalizar unicamente o nível nacional e ocupando-se também com a Região como unidade de trabalho. Ações como estas são oportunidades para os estudantes vivenciarem relações de interculturalidade e desenvolverem rotinas de trabalho bilíngues, experiências fundamentais para os objetivos expressos na documentação política da relação entre os dois países (BRASIL, 2008).

Além disso, a língua transfronteiriça é uma expressão dos processos de hibridização e interculturalidade que ocorrem nessa fronteira internacional, recriando identidades e também redefinindo os limites da alteridade. Assim, para Roberto Corrêa, "a identidade de si mesmo e a alteridade são, em parte, expressas por meio da língua. Constitui ela uma forma de capital cultural coletivo e, simultaneamente, pode ser vista como forma simbólica cuja espacialidade assume características específicas” (2008, p.16).

A identidade passa por processos de reconfiguração a partir de uma concordância cultural e de tensões que se expressam nas tramas cotidianas de negação e afirmação cultural que ocorrem de geração para geração a partir do contato com o "outro".

Dessa forma, através da vivência cotidiana no espaço transfronteiriço, sujeitos de diferentes nacionalidades e identidades constroem novas formas de identificação que podem contribuir para diluir as tensões identitárias entre brasileiros e paraguaios, dentro e fora da "faixa de fronteira" internacional, construindo novos sabores e novos saberes sobre as fronteiras. 


\title{
Considerações finais
}

A fronteira internacional Brasil-Paraguai apresenta-se como um espaço dinâmico e complexo em função da contiguidade física entre os dois espaços e da efetiva mobilidade populacional para ambos os lados do limite internacional. Ressalto ainda que, junto à mobilidade populacional, coexistem problemas históricos de oposição entre brasileiros e paraguaios, os quais resultam em uma intensificação de conflitos entre esses povos.

A interculturalidade no contexto da fronteira Brasil-Paraguai em que se insere esta pesquisa representa uma postura teórica e política que propõe uma prática dialógica no que se refere a duas ou mais culturas existentes.

Como considera Reinando Fleury (2003), a interculturalidade implica no reconhecimento do caráter inter-relacional e fluido das relações humanas, de modo que não há algo dado e imutável espacial e temporalmente, especialmente no que diz respeito às relações humanas, dentro ou fora da "faixa de fronteira".

\begin{abstract}
As relações de identidade/alteridade, entre brasileiros e paraguaios, a partir da perspectiva intercultural podem promover novas práticas de diálogos culturais. A interculturalidade contribui para a "construção de novas formas de pensar, agir e ver o mundo", nas quais as diferenças culturais são consideradas como características eminentes das sociedades e uma opção autônoma por parte dos grupos e sujeitos em exercê-la, sendo este um direito coletivo e individual. (TERENCIANI, 2011, p.187)
\end{abstract}

Assim, a fronteira apresenta-se não apenas como uma expressão político-administrativa, mas como esfera da vida cotidiana dos sujeitos, que diariamente se deparam com limites para a efetivação de diálogos culturais e identitários.

Desse modo, ela age também como um importante elemento de aproximação entre brasileiros e paraguaios, contribuindo para que uma nova cultura e uma nova identidade se formem, marcadas por este trânsito característico da cultura e identidade transfronteiriças. Ademais, de maneira inconsciente, a interculturalidade se faz presente na fronteira entre Brasil-Paraguai, de modo que brasileiros e paraguaios vivem, em diferentes escalas e em momentos distintos, elementos de ambas as culturas.

Queremos finalizar esta reflexão, lembrando que brasileiros e paraguaios na fronteira Brasil-Paraguai, no constante movimento de ir e vir para além dos limites internacionais, podem transformar práticas socioculturais já estabelecidas de oposição entre "eu” e o "outro", criando por meio do contato multi/intercultural, incluindo o que ocorre nos ambientes 
OLIVEIRA, Lilia Odete Nantes de. A linguagem como construção X desconstrução das identidades diversas: multi/interculturalidade escolar em escolas da fronteira.

escolares, novas formas de pensar e viver a fronteira, na qual a pluralidade e o diálogo cultural caracterizam-se como pressupostos para a (re)criação cultural e identitária. 


\section{Referências bibliográficas}

BAGNO, M. et al. Língua materna: letramento, variação \& ensino. São Paulo: Parábola, 2002.

BHABHA. H. K. O local da cultura. Trad. Myriam Ávila et al. Belo Horizonte: Ed. UFMG, 2010.

BRASIL. Ministerio de Educación, Ciencia y Tecnología e Ministério da Educação. Escolas de Fronteira. Brasília e Buenos Aires, 2008.

CANCLINI, N. G. Culturas híbridas: estratégias para entrar e sair da modernidade. 4.ed. São Paulo: UNESP, 2011.

CANDAU, V. Diferentes, desiguais e desconectados. Trad. Luiz Sérgio Henriques. 3.ed. Rio de Janeiro: Editora da UFRJ, 2009.

CAVALCANTI, M. C.; MOITA LOPES, L. P. Implementação de Pesquisa na Sala de Aula de Língua Estrangeira. Trabalhos em Linguísticas Aplicada, 1991.

CAVALCANTI, MARILDA C. Estudos sobre Educação Bilíngue e Escolarização em Contextos de Minorias Linguísticas no Brasil. 1999. p.385-417.

. Multiculturalismo e educação: questões, tendências e perspectivas. In: CANDAU, V. M. F. (Org.). Sociedade, educação e cultura(s): questões e propostas. Petrópolis: Vozes, 2008.

CORRÊA, R. L. Formas simbólicas e espaço. [S.1.: s.ed.], 2008. Disponível em: http://www.igeo.ufrj.br/robertolobatocorrea. Acesso em: 5 ago 2013.

DALINGHAUS, I. V. Alunos brasiguaios em escolas de fronteira Brasil/Paraguai: um estudo linguístico sobre aprendizagem do Português em Ponta Porá, MS. Cascavel: UNIOESTE, 2009.

FLEURY, R. M. Políticas da diferença: para além dos estereótipos na prática educacional. Educação \& Sociedade, Campinas, v.XXVII, n.95, p.495-520, 2006.

. Entre limites e limiares de culturas: educação na perspectiva intercultural. In: FLEURY, R. M. (Org.) Educação intercultural: mediações necessárias. Rio de Janeiro: DP\&A, 2003.

; AZIBEIRO, N. Esperança. Paradigmas interculturais emergentes na educação popular. In: II Congresso Internacional: Cotidiano - Diálogos sobre Diálogos. Grupalfa. Niterói: Universidade Federal Fluminense, 2008.

; LEITE, M. S. A didática na perspectiva multi/intercultural em ação: construindo uma proposta. Cadernos de Pesquisa, v.XXXVII, n.132, p.731-58, set/dez 2007. 
GÁUDIO, R. S. del; BRAGA, R. B. A Geografia, a educação e a construção da ideologia nacional. Terra Livre, São Paulo, ano 23, v.I, n.28, p.177-96, jan/jul 2007.

MEY, J. L. Etnia identidade e língua. Trad. Maria da Glória de Moraes. In: SIGNORINI, I. Língua(gem) e identidade. Campinas: Mercado de letras, 1998.

MOITA LOPES, L. P. da. Identidades Fragmentadas: A construção discursiva de raça, gênero e sexualidade na escola. Campinas: Mercado de Letras, 2002.

ORLANDI, E. P. Língua brasileira e outras histórias: discurso sobre a língua e ensino no Brasil. Campinas: Editora RG, 2009.

PEREIRA, R. M. F. A. A Geografia na escola. In: Da Geografia que se ensina à gênese da Geografia moderna. 2. ed. Florianópolis: Ed. da UFSC, 1999, p.21-49.

PEREIRA, Jacira Helena do Valle. Brasiguaios ou fronteiriços? A noção de habitus para compreender o pertencimento cultural na fronteira brasil-paraguai. Revista do Centro de Educação e Letras, v.15, n.2, p.129-48, ago-dez 2013.

SAID, E. Reflexões sobre o exílio. São Paulo: Companhia das Letras, 2003.

SANTOS, B. de S. Pela mão de Alice: o social e o político na pós-modernidade. Porto: Edições Afrontamento, 1994.

Modernidade, identidade e a cultura de fronteira. Tempo Social. Rev. Sociol. USP, v.V, n.1-2, p.31-52, nov 1994.

SOUCHAUD, Sylvain. Geografía de lamigración brasileña em Paraguay. Asunción: UNFPA-ADEPO, 2007.

TEDESCHI, L. A. Interculturalidade: igualdade e diferença em debate. In: TEDESCHI, L. A. et al. Abordagens interculturais. Porto Alegre: Martins Livreiro-Editor, 2008.

TERENCIANI, C. Interculturalidade e ensino de Geografia em escolas na fronteira BrasilParaguai em Mato Grosso do Sul. Sine loco, PPGG/UFGD, 2011. Dissertação de Mestrado apresentada à Coordenação de Pós-Graduação em Ciências Humanas. 